\title{
Estimating Genetic Diversity in Durum and Bread Wheat Cultivars from Turkey using AFLP and SAMPL Markers
}

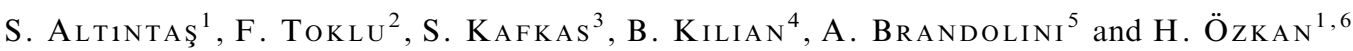 \\ ${ }^{1}$ Department of Field Crops, Faculty of Agriculture, University of Cukurova, 01330, Adana, Turkey; ${ }^{2}$ Seed Science and \\ Technology Program, Vocational School of Kozan, University of Cukurova Kozan, Adana, Turkey; ${ }^{3}$ Department of \\ Horticulture, Faculty of Agriculture, University of Cukurova, 01330, Adana, Turkey; ${ }^{4}$ Max Planck Institute for Plant Breeding \\ Research, Köln, Germany; ${ }^{5}$ CRA-Istituto Sperimentale per la Cerealicoltura, 26866, S. Angelo Lodigiano, Italy; ${ }^{6}$ Corresponding \\ Author, E-mail: hozkan@mail.cu.edu.tr
}

With 2 figures and 2 tables

Received December 19, 2006/Accepted May 3, 2007

Communicated by P. Wehling

\begin{abstract}
Since 1925, more than 100 wheat varieties were developed and released in Turkey, and many more were introduced from abroad, but no systematic analysis of their genetic diversity has been performed yet. In this research, a total of 34 domestic and foreign cultivars (12 durum and 22 bread wheats), released in Turkey between 1936 and 2000, were fingerprinted by means of five amplified fragment length polymorphism and three selective amplification of microsatellite polymorphic loci (SAMPL) primer combinations, to evaluate their genetic variation and to determine the existence of cultivar-specific bands. Among the 344 amplicons scored, 214 were polymorphic. The primer combination $\mathrm{E}_{\mathrm{ACG}} / \mathrm{M}_{\mathrm{AGG}}$ yielded the highest number and the primer combination SAMPL-6/M AGA produced the lowest number of polymorphic bands. Most cultivars were molecularly very similar, although a few distinct ones (the durum wheat 'Kunduru-1149' and the bread wheat 'Ikizce96') were also identified. Seven cultivar-specific markers for different bread wheat cultivars ('Golia', 'Seri-82', 'Adana-99', 'Pandas' and 'Sertak-52') and six cultivar-specific markers for durum wheat cv 'Kunduru' were observed. Our results show that genetic diversity among old and present-day wheat cultivar commonly grown in Turkey is limited.
\end{abstract}

Key words: Turkey — durum wheat — bread wheat - AFLP SAMPL

During the last 35 years wheat production in Turkey steadily increased, reaching about 21 million tons/year out of 9 million ha (the seventh largest area in the world). Meanwhile, genetic resources from Turkey contributed greatly to the increase of wheat production in many countries. Germplasm exploration and collection missions led to the evaluation of sampled materials in different countries, and several landraces (e.g. Turkey Red) were largely utilized to breed new varieties. In Turkey modern wheat breeding started in 1925: its main goal was to select, from local population, lines adaptated to the different regions of the country. This breeding effort quickly produced cultivars such as 'Yayla-305' and 'Ak-702' (Gökgöl 1939). In 1967 the National Wheat Release and Training Project was established, with the contribution of international organizations, resulting in the Turkish Green Revolution. Since then many cultivar were introduced from foreign countries, specifically targeting different areas. The national breeding program, meanwhile, developed over 100 wheat cultivars, most of which had a significant impact on the economy.
Information on germplasm diversity and genetic relationships among cultivar are critical in wheat improvement. Genetic similarities might be evaluated by means of pedigree analysis (Barrett et al. 1998) or by assessing morphological traits (Schut et al. 1997) as well as biochemical (Metakovsky and Branlard 1998) or, more recently, DNA markers (Barrett et al. 1998, Pagnotta et al. 2005). DNA markers are useful complements to the morphological and physiological characterization of cultivars because they are plentiful, are not influenced by plant tissue or environmental effects, and allow cultivar identification very early in plant development (Manifesto et al. 2001). Today, DNA markers are largely employed in diversity studies, following different techniques such as RFLP (Kim and Ward 1997, Paul et al. 1998), RAPD (Sun et al. 1998), sequence-tagged site PCR (STS-PCR) (Chen et al. 1994), amplified fragment length polymorphism (AFLP) (Barrett and Kidwell 1998, Burkhamer et al. 1998), Selective amplification of microsatellite polymorphic loci (SAMPL) (Roy et al. 2002) and SSR (Plaschke et al. 1995).

The amplified fragment length polymorphism technique (Vos et al. 1995) detects high levels of DNA polymorphism and is extremely promising for fingerprinting, mapping and genetic diversity studies. One of its main advantages is the high multiplex ratio, which means that large numbers of amplified products are generated in a single reaction (Powell et al. 1996). Furthermore, reproducibility, heritability and intra-specific homology of AFLPs have already been demonstrated (Mackill et al. 1996).

Selective amplification of microsatellite polymorphic loci, a microsatellite-based marker system, is a modification of the AFLP methodology (Roy et al. 2002): it differs in that the selective amplification is achieved using one AFLP primer in combination with one SAMPL primer (Rakoczy-Trojanowska and Bolibok 2004). The use of a SAMPL primer in combination with an AFLP primer is particularly suitable when low genetic variation is expected, since the primers target the hyper-variable microsatellite loci (Witsenboer et al. 1997).

So far, the genetic diversity of Turkish-grown wheat cultivars are not well understood. Objectives of this work were therefore (i) to characterize by AFLP and SAMPL markers twelve durum wheat and twenty-two bread wheat cultivars, old and modern, grown in Turkey; (ii) to determine 
the existence of cultivar-specific amplicons; (iii) to assess the relative informativeness of AFLPs and SAMPLs.

\section{Materials and Methods}

Plant materials: A total of thirty-four wheat cultivars, including 12 durum (Triticum turgidum ssp. durum) and 22 bread (T. aestivum ssp. aestivum) wheat cultivars, most of them bred in Turkey during the last 70 years, were fingerprinted in this study. Name/pedigree of the cultivars are presented in Table 1.

DNA extraction and AFLP/SAMPL analyses: Leaf samples were collected from each cultivar, frozen in liquid nitrogen and stored at $-70^{\circ} \mathrm{C}$ until use. Genomic DNA was extracted from leaf tissue by the CTAB method of Doyle and Doyle (1987) with minor modifications (Kafkas et al. 2005). The AFLP and SAMPL amplifications were performed according to Vos et al. (1995), with minor modifications (Ozkan et al. 2005), using five AFLP primer combinations $\left(\mathrm{E}_{\mathrm{ACC}} / \mathrm{M}_{\mathrm{AGC}}, \mathrm{E}_{\mathrm{ACG}} / \mathrm{M}_{\mathrm{ACC}}, \mathrm{E}_{\mathrm{ACG}} / \mathrm{M}_{\mathrm{ACT}}, \mathrm{E}_{\mathrm{ACG}} / \mathrm{M}_{\mathrm{AGG}}\right.$, $\left.\mathrm{E}_{\mathrm{ACG}} / \mathrm{M}_{\mathrm{AGT}}\right)$ and three SAMPL primer (5'-ACACACACACACACATATAA-3') combinations (SAMPL6/M $\mathrm{M}_{\mathrm{AGA}}$, SAMPL6/M $\mathrm{M}_{\mathrm{ATA}}$, SAMPL6/M $\mathrm{MTG}_{\mathrm{ATG}}$.

A total of $10 \mu \mathrm{l}$ of the AFLP and SAMPL selective amplification product was mixed with $10 \mu \mathrm{l}$ of loading buffer, denatured at $94^{\circ} \mathrm{C}$ for $5 \mathrm{~min}$ and placed on ice. After a pre-run electrophoresis at $60 \mathrm{~W}$ for $30 \mathrm{~min}$, about $3 \mu \mathrm{l}$ of mixture were loaded onto a $4.5 \%(\mathrm{w} / \mathrm{v})$ polyacrylamide denaturing gel with $0.5 \mathrm{x}$ TBE buffer and run at $60 \mathrm{~W}$ until the loading dye reached the bottom of the gel. The gels were dried at $80^{\circ} \mathrm{C}$ for $3 \mathrm{~h}$; an autoradiographic Hyperfilm-MP (Amersham, England) was exposed to the gels for 2 days.
Band scoring and data analysis: The AFLP and SAMPL bands were visually scored as present (1) or absent (0): only the clearest and strongest bands were recorded and used for the analysis. The bands were independently scored twice, by two different observers. The ability of the most informative primer pairs to differentiate between genotypes was assessed by calculating their resolving power (Rp) according to Prevost and Wilkinson (1999) using $R p=\sum I_{b}$, where $I_{b}$ is band informativeness and $I_{b}=1-[2 \times(0.5-p)]$, where $p$ is the proportion of genotypes containing band.

Genetic distances were calculated by the PAUP $4.0 \mathrm{~b}$ program (Swofford 1998) according to the method developed by Nei and $\mathrm{Li}$ (1979). These distances were used to build an unweighted pair-group method with arithmetic means (UPGMA) tree. Principal Components Analysis (PCA) was carried out using the NTSYS-pc 2.11 software (Rholf 1993).

\section{Results}

Five AFLP and three SAMPL primer combinations were used to characterize 12 durum wheat and 22 bread wheat cultivars. Out of a total of 344 amplicons, $214(62 \%)$ were polymorphic, averaging 43 total bands and 26.8 polymorphic bands per primer combination (Table 2). The five AFLP primer sets amplified 251 bands (64\% of them polymorphic), with an average of 50.2 total and 32 polymorphic bands per primer pair. In SAMPL analysis, the three primer combinations amplified 93 bands (58\% of them polymorphic), with an average of 31 total and 18 polymorphic fragments. The individual primer pairs produced between 30 and 57 bands,

Table 1: Name, year of release, pedigree and origin of the 34 wheat cultivars used in this study

\begin{tabular}{|c|c|c|c|}
\hline Name of cultivars & Year of release & Pedigree & Origin \\
\hline \multicolumn{4}{|c|}{ T. turgidum ssp. durum } \\
\hline Dicle-74 & 1975 & RojoAlicanteE/4*Tehuacan60//Stewart63/3/(S) & Mexico \\
\hline Gediz-75 & 1976 & LD357E/TC2//Jori'S' & Mexico \\
\hline Diyarbakır-81 & 1981 & LD393//BEL116E/2*TC/3/CIT71 & Turkey \\
\hline Harran-95 & 1995 & Korifla//D.S-15/Geiger & Turkey- Mexico \\
\hline Ceylan-95 & 1995 & STORK'S'RABI 'S' & Turkey- Mexico \\
\hline Saricanak-98 & 1998 & DACK/GEDIZ//USPA575 & Turkey- Mexico-Syria \\
\hline Kunduru-1149 & 1967 & Landrace & Turkey \\
\hline Çakmak-79 & 1979 & UVY162/61.130 & Turkey \\
\hline Balcal1-2000 & 2000 & Stn 'S' & Turkey \\
\hline Balcal1-85 & 1985 & Bittern 'S' & Turkey \\
\hline Amanos-97 & 1997 & & Turkey \\
\hline Selçuklu-97 & 1997 & 073-44*2/Ovi/3/DF21-72//61-130/Uvy162 & Turkey \\
\hline \multicolumn{4}{|c|}{ T. aestivum ssp. aestivum } \\
\hline Gerek-79 & 1979 & MEN'S'//MY48/4-11/3/YY305 & Turkey \\
\hline Atay-85 & 1985 & Hyslop/7Cerros66 & Turkey \\
\hline Katia-I & 1990 & Chebros/BEZ & Bulgaria \\
\hline Gün-91 & 1991 & F35.70/Mochis73 & Turkey-Mexico \\
\hline Dağdas-94 & 1994 & 093-44/AU//SIHHE & Turkey \\
\hline Kutluk-94 & 1994 & KSK//INIA/LFN/3/Çalibasan & Turkey \\
\hline Pehlivan & 1995 & $\mathrm{BEZ} / \mathrm{TUR} / 5 / \mathrm{CFN} / \mathrm{BEZ}$ & Turkey \\
\hline Kirgiz-95 & 1995 & Domanic*2/AU & Turkey \\
\hline Ikizce- 96 & 1996 & $\mathrm{ATR} * 2 / 7 \mathrm{C} / / \mathrm{BL}$ & Turkey \\
\hline Pandas & 1984 & Orso//BEZ-1/S1/GEN7/Marzotto & Italy \\
\hline Seri-82 & 1992 & Vee‘ 5 ' & Turkey-Mexico \\
\hline Kasifbey-95 & 1995 & PFAU 'S' & Turkey-Mexico \\
\hline Golia & 1989 & Manital/Orso & Italy \\
\hline Gönen-98 & 1998 & $8156 / \mathrm{Mara} / / \mathrm{BB}$ & Turkey \\
\hline Kıraç-66 & 1966 & Florence/Yayla305 & Turkey \\
\hline Bolal & 1970 & Cheyenne/Kenya/Mentana & USA \\
\hline Sertak -52 & 1936 & Landrace & Turkey \\
\hline Nurkent & - & {[} & Turkey \\
\hline Genç-88 & 1988 & Cno'S' $/ \mathrm{Nac} / / \mathrm{Cc} / /$ Inia/3/Bb/Nar59 & Turkey \\
\hline Yayla-305 & 1939 & Landrace & Turkey \\
\hline Bezostaya & - & - & Russia \\
\hline Adana-99 & 1999 & PFAU/Seri-82/BOW & Turkey-Mexico \\
\hline
\end{tabular}


Table 2: Number of total and polymorphic bands, percentage of polymorphism, and resolving powers of primer pairs detected in the DNA fingerprinting of 14 durum and 20 common wheat cultivars with AFLP and SAMPL markers

\begin{tabular}{|c|c|c|c|c|c|c|c|c|c|c|c|c|}
\hline \multirow[b]{2}{*}{$\begin{array}{l}\text { Primer } \\
\text { combinations }\end{array}$} & \multicolumn{4}{|c|}{ Durum and common wheat } & \multicolumn{4}{|c|}{ Durum wheat } & \multicolumn{4}{|c|}{ Bread wheat } \\
\hline & $\begin{array}{l}\text { Total no. } \\
\text { of bands }\end{array}$ & $\begin{array}{c}\text { No. of } \\
\text { polymorphic } \\
\text { bands }\end{array}$ & $\begin{array}{l}\mathrm{P} \\
(\%)\end{array}$ & $(\mathrm{Rp})$ & $\begin{array}{l}\text { Total no. } \\
\text { of bands }\end{array}$ & $\begin{array}{l}\text { No. of } \\
\text { polymorphic } \\
\text { bands }\end{array}$ & $\begin{array}{l}\mathrm{P} \\
(\%)\end{array}$ & $(\mathrm{Rp})$ & $\begin{array}{l}\text { Total no. } \\
\text { of bands }\end{array}$ & $\begin{array}{c}\text { No. of } \\
\text { polymorphic } \\
\text { bands }\end{array}$ & $\begin{array}{l}\mathrm{P} \\
(\%)\end{array}$ & $(\mathrm{Rp})$ \\
\hline $\mathrm{E}_{\mathrm{ACC}} / \mathrm{M}_{\mathrm{AGC}}$ & 45 & 27 & 60 & 29.1 & 44 & 24 & 54 & 24.6 & 45 & 26 & 58 & 30.2 \\
\hline $\mathrm{E}_{\mathrm{ACG}} / \mathrm{M}_{\mathrm{ACC}}$ & 49 & 27 & 55 & 33.6 & 47 & 12 & 26 & 10.6 & 49 & 17 & 35 & 19.9 \\
\hline $\mathrm{E}_{\mathrm{ACG}} / \mathrm{M}_{\mathrm{ACT}}$ & 57 & 34 & 59 & 40.8 & 53 & 18 & 34 & 17.6 & 57 & 29 & 51 & 35.5 \\
\hline $\mathrm{E}_{\mathrm{ACG}} / \mathrm{M}_{\mathrm{AGG}}$ & 55 & 42 & 76 & 54.1 & 55 & 21 & 38 & 24.3 & 55 & 31 & 56 & 45.5 \\
\hline $\mathrm{E}_{\mathrm{ACG}} / \mathrm{M}_{\mathrm{AGT}}$ & 45 & 30 & 67 & 42.2 & 44 & 23 & 52 & 20.0 & 45 & 18 & 40 & 25.0 \\
\hline Subtotal/Average & $251 / 50.2$ & $160 / 32$ & 64 & & $243 / 48.6$ & $98 / 19.6$ & 40 & & $251 / 50.2$ & $121 / 24.2$ & 48 & \\
\hline SAMPL6/M AGA & 30 & 16 & 53 & 25.1 & 30 & 10 & 33 & 10.2 & 30 & 11 & 37 & 19.8 \\
\hline SAMPL6/M ATA & 30 & 18 & 60 & 23.1 & 30 & 12 & 40 & 10.7 & 30 & 12 & 40 & 15.6 \\
\hline SAMPL6/M ATG & 33 & 20 & 61 & 28.3 & 33 & 19 & 58 & 26.8 & 33 & 19 & 58 & 26.0 \\
\hline Subtotal/average & $93 / 31.0$ & $54 / 18$ & 58 & & $93 / 31.0$ & $41 / 13.7$ & 44 & & $93 / 31$ & $42 / 14.0$ & 45 & \\
\hline Total/average & $344 / 43.0$ & $214 / 26.8$ & 62 & & $336 / 42.0$ & $139 / 17.4$ & 39 & & $344 / 43.0$ & $163 / 20.4$ & 47 & \\
\hline
\end{tabular}

P, Polymorphism; Rp, Resolving power.

while the percentage of polymorphism per primer combination ranged from $53 \%$ to $76 \%$. The same trend is observed also within species: in durum wheat polymorphism varied between $26 \%$ and $58 \%$ (mean 39\%), while in bread wheat varied from $35 \%$ to $58 \%$ (mean $47 \%$ ). The average number of total and polymorphic bands was slightly lower in durum wheat compared to bread wheat.

The resolving power ( $\mathrm{Rp})$ of the different primer combinations (Table 2) ranged between 23.1 and 54.1 (durum wheat: 10.2-26.8; bread wheat: 15.6-45.5). According to the $\mathrm{Rp}$ values of all primer combinations, the AFLP primers discriminated the 34 wheat cultivars better than the SAMPL primers.

The UPGMA dendrogram (Fig. 1) clearly split wheat cultivars according to their species/ploidy: subcluster I gathered all T. turgidum (AABB) and subcluster II grouped all T. aestivum (AABBDD). Within species, cluster I was divided into three sub-clusters: IA (eight genotypes), IB (three genotypes) and IC (only 'Kunduru-1149'); the eight durum wheat cultivar of sub-cluster IA were further divided into two groups, one with five genotypes and the other one with three genotypes. Cluster II was also divided into three clusters: IIA (19 genotypes), IIB (two genotypes) and IIC (only one genotype, cv. 'Ikizce'). The 19 common wheat cultivars of subcluster IIA were further divided in two groups, one with 9 genotypes and the other one with 10 genotypes. To test the goodness of fit of the UPGMA cluster analysis on our AFLP and SAMPL datas, the MxComp routine in NTSYS-pc was used to compute the cophenetic value. The correlation $r=$ 0.925 , obtained for the UPGMA method, suggests a very good fit of the original data with the final dendrogram.

The principal components analysis results are depicted in Fig. 2. The first three components of PCA accounted for $44.79 \%$ of total variation and the 34 genotypes were well separated into two groups, according to ploidy level. Kunduru-1149 (durum wheat) and 'Ikizce-96' (bread wheat) were clearly different from the other cultivars.

The average pair-wise genetic distance (proportion of different bands) among all genotypes was 0.128 , ranging from 0.013 to 0.357 (data not shown). The average genetic distance between durum wheat and bread wheat cultivars was 0.304 . In durum wheat the mean was 0.132 , varying from 0.072 ('Saricanak-Balcali-85') to 0.216 ('Selcuklu-Kunduru-1149'), while in bread wheat the mean was 0.127 , ranging from 0.066 ('Genc-88- Nurkent') to 0.214 ('Dagdas-Ikizce').

\section{Discussion}

AFLP and SAMPL have been extensively used as molecular marker systems for detecting DNA polymorphism in wheat. In this study, the use of five AFLP and three SAMPL primer pairs resulted in polymorphism ranging from $53 \%$ to $76 \%$, high levels when compared to previous studies: for example, Barrett and Kidwell (1998) found $11.8 \%$ polymorphisms among 54 genotypes, using 16 primer pairs; Roy et al. (2002) found $49.4 \%$ polymorphisms among 55 wheat cultivars; Hazen et al. (2002) detected $23.2 \%$ polymorphisms in 44 genotypes, using 8 primer pairs; Bohn et al. (1999) reported $21.0 \%$ of polymorphism with 11 wheat genotypes, using 11 primer pairs. However, genotypes and primer pairs in the above-mentioned researches were different, making the results not easily comparable.

The efficiency of the different marker techniques for estimating DNA polymorphism in wheat is variable. For instance, Joshi and Nguyen (1993), among 15 wheat cultivars, used 40 RAPD primers and observed 1.8 polymorphic bands per primer, while, Sun et al. (1996) detected seven polymorphic bands per primer analysing 46 genotypes of T. aestivum and $T$. spelta with 26 RAPD primers. For RFLPs, the number of polymorphic bands per probe/enzyme combination in bread wheat ranged from 1.2 in 222 genotypes (Kim and Ward 1997) to 3.3 in 124 cultivar (Paul et al. 1998). ISSR primers detected 3.7 polymorphisms per primer (Nagaoka and Ogihara 1997), while microsatellites were more polymorphic, with 6.2 alleles/bands (Plaschke et al. 1995). SAMPL primer pairs detected 21.5 polymorphism per primer pair in 55 wheat cultivars (Roy et al. 2002). In our study, using only five AFLP and three SAMPL primer pairs, we observed 344 fragments, with an average of 26.8 polymorphic loci per primer pair (17.4 among durum wheat cultivars and 20.4 among bread wheat cultivars). Therefore, they detected at least three to four times more polymorphisms per primer pair than any other molecular marker technique. Thus AFLP, alone or combined to SAMPL, is probably the most efficient marker system also in the case of wheat.

Seven cultivar-specific markers for bread wheat and six cultivar-specific markers for durum wheat cultivars were found 


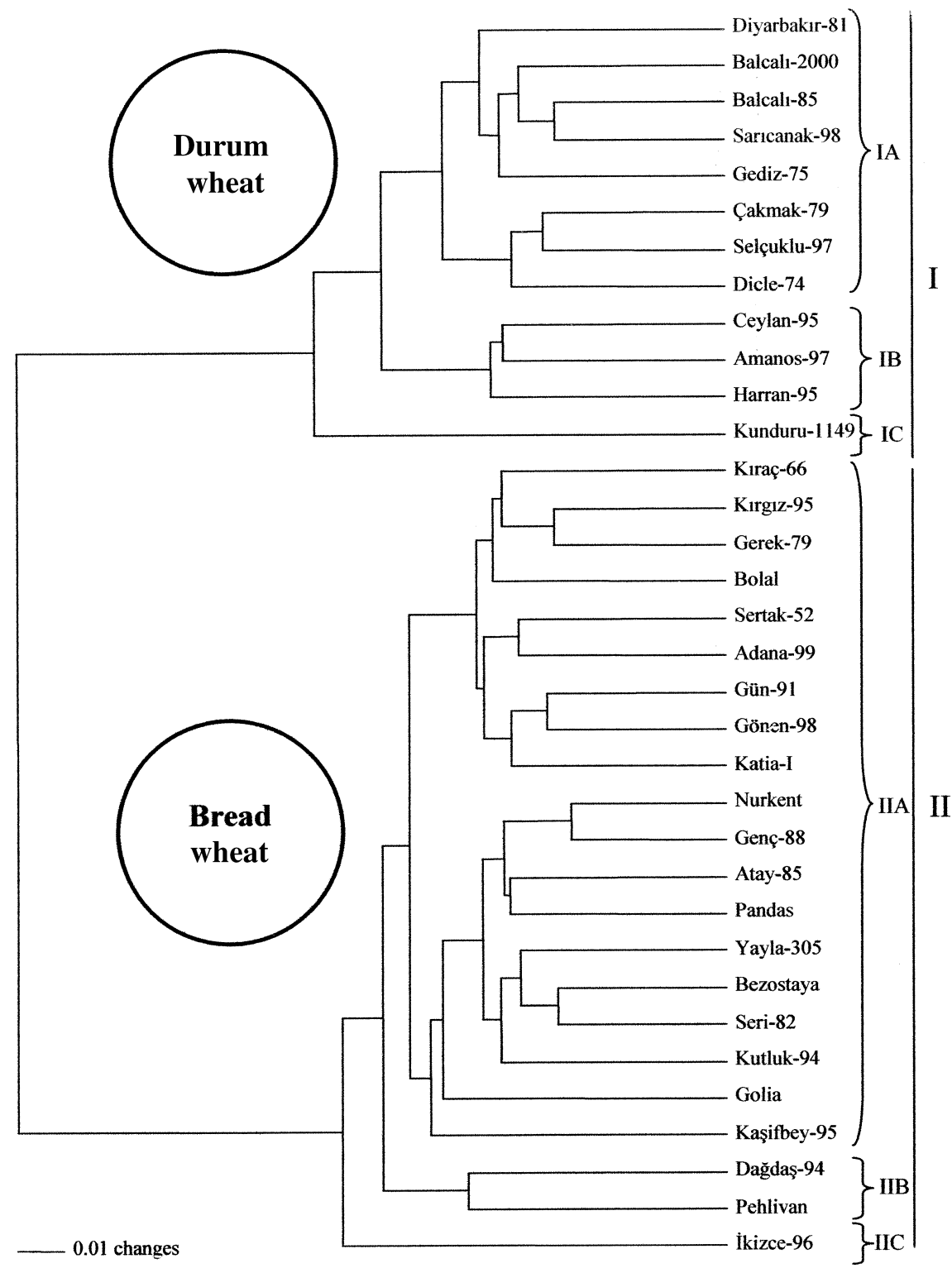

Fig. 1: UPGMA dendrogram of 12 durum and 22 bread wheats from Turkey

among the 214 polymorphic bands observed. In bread wheat the cultivar-specific fragments were distributed between five different cultivars ('Golia', 'Seri-82', 'Adana-99', Pandas and 'Sertak-52'). In durum wheat, however, they were all restricted to 'Kunduru-1149'. If these findings are confirmed over a broader range of accessions, the unique bands could be useful for the identification of these six cultivars, directly or after development of sequence-tagged site primers.

A poor agreement between the AFLP/SAMPL clustering and the available pedigree informations is evident for both species. For example, 'Katia-I' and 'Pehlivan' share one common parent, but consistently appear in different subclusters. It has to be remembered that low to moderate correlations between genetic diversity estimations based on pedigree analysis and on RAPD data were reported for bread wheat (Kudryavtsev et al. 2003, Sun et al. 2003), although Barrett et al. (1998) reported that genetic distances for AFLP based on enzyme combination $P s t \mathrm{I} / \mathrm{MseI}$ were better correlated with pedigree than estimations based on EcoRI/MseI.
Our data seem to indicate a low genetic diversity among the wheat cultivars cropped in Turkey. This observation agrees with the results of Chao et al. (1989), Devos and Gale (1992) and Shoaib and Arabi (2006). However, Burkhamer et al. (1998), using AFLPs, found a genetic similarity of 0.55 (range from 0.34 to 0.81 ) in a pool of 10 hard red spring wheat cultivars. The narrow genetic basis of modern wheat cultivars is well known and demonstrated by both pedigree (Cox et al. 1986) and molecular analysis (Chen et al. 1994, Sun et al. 1996).

Most of the Turkish wheat cultivars used in this study were bred, directly or indirectly, from CIMMYT germplasm. Actually, only three wheat cultivars trace back exclusively to Turkish landraces (durum wheat Kunduru and bread wheats 'Sertak-52' and 'Yayla-305'). This suggests that old Turkish cultivars have scarcely been included within the genetic pool used for breeding modern varieties and highlights the primary role of the germplasm developed by CIMMYT.

Our results have relevant implications for Turkey wheat breeding. First, present day commonly-grown Turkish wheat 
Fig. 2: Patterns of relationship among 12 durum and 22 bread wheat cultivars as revealed by Principal Component Analysis based on AFLP and SAMPL data

cultivars have a narrow genetic diversity, most likely as the results of selection pressure and genetic drift in breeding programs. The genetic relationships observed among these cultivars, therefore, are helpful for current and future breeding programs in order to select genetically distinct parents. Second, the narrow genetic diversity observed among Turkish wheat cultivars suggests the need of broadening the genetic base of wheat breeding materials, including local landraces. This is even more relevant since Dreisigacker et al. (2004), Karagöz and Zencirci (2004) and Zencirci and Karagöz (2005) reported that some Anatolian wheat landraces host a broad genetic diversity, an observation substantiated also by our study: 'Kunduru', the most diverse durum wheat cultivar, was directly selected from a landrace. This study shows that the Turkish landraces of durum and bread wheat are quite unique and markedly differ from other wheat germplasm. Further surveys are urgently needed to elucidate the genetic structure of the Turkish wheat genepool and to identify new useful allelles.

\section{Acknowledgements}

The author (HO) gratefully acknowledges the support of the Turkish Government Planning Organization (Project\# 2002K120180-B) and the Research Foundation of Cukurova University in Turkey (Project\# ALT.2001.9).

\section{References}

Barrett, B. A., and K. K. Kidwell, 1998: AFLP-based genetic diversity assessment among wheat cultivar from the Pacific Northwest. Crop Sci. 38, 1261-1271.

Barrett, B. A., K. K. Kidwell, and P. N. Fox, 1998: Comparison of AFLP and pedigree-based genetic diversity assessment methods using wheat cultivar from the Pacific Northwest. Crop Sci. 38, $1271-1278$.

Bohn, M., H. F. Utz, and A. E. Melchinger, 1999: Genetic similarities among winter wheat cultivars determined on the basis of RFLPs, AFLPs and SSRs and their use for predicting progeny variance. Crop Sci. 39, 228-237.

Burkhamer, R. L., S. P. Lanning, R. J. Martens, J. M. Martin, and L. E. Talbert, 1998: Predicting progeny variance from parental divergence in hard red spring wheat. Crop Sci. 38, 243-248.

Chao, S., P. J. Sharp, A. J. Worland, E. J. Warham, R. M. D. Koebner, and M. D. Gale, 1989: RFLP-based genetic maps of wheat homeologous group 7 chromosomes. Theor. Appl. Genet. 78, 495-504.

Chen, H. B., J. M. Martin, M. Lavin, and L. E. Talbert, 1994: Genetic diversity in hard red spring wheat based on sequence-targeted-site PCR markers. Crop Sci. 34, 1628-1632.

Cox, T. S., J. P. Murphy, and D. M. Rodgers, 1986: Changes in genetic diversity in the red winter regions in the United States. Proc. Natl. Acad. Sci. U. S. A. 83, 5583-5586.

Devos, K. M., and M. D. Gale, 1992: The use of randomly amplified polymorphic DNA markers in wheat. Theor. Appl. Genet. 84, $567-572$.

Doyle, J. J., and J. L. Doyle, 1987: A rapid DNA isolation procedure for small quantities of fresh leaf tissue. Phytochem. Bull. 19, 11-15.

Dreisigacker, S., P. Zhang, M. L. Warburton, M. VanGinkel, D. Hoisington, M. Bohn, and A. E. Melchinger, 2004: SSR and pedigree analyses of genetic diversity among CIMMYT wheat lines targeted to different megaenvironment. Crop Sci. 44, 381-388.

Gökgöl, M., 1939: Turkish Wheats, Vol. II. Yeşilköy Seed Breeding Institute Publications. No:14, Tan Press, Istanbul, Turkey, 955 pp. (In Turkish).

Hazen, P. S., P. Leroy, and R. Ward, 2002: AFLP in Triticum aestivum L. Patterns of diversity and genome distributrion. Euphytica 125, 89-102.

Joshi, C. P., and H. T. Nguyen, 1993: RAPD (random amplified polymorphic DNA) analysis based intervarietal genetic relationships among hexaploid wheats. Plant Sci. 93, 95-103. 
Kafkas, S., H. Ozkan, and M. Sutyemez, 2005: DNA polymorphism and assessment of genetic relationships in walnut genotypes based on AFLP and SAMPL markers. J. Am. Soc. Hortic. Sci. 130, 585-590.

Karagöz, A., and N. Zencirci, 2004: Variation in wheat (Triticum spp.) landraces from different altitudes of three regions of Turkey. Genet. Resour. Crop Evol. 52, 775-785.

Kim, H. S., and R. W. Ward, 1997: Genetic diversity in Eastern U.S. soft winter wheat (Triticum aestivum L. Em. Thell.) based on RFLPs and coefficient of parentage. Theor. Appl. Genet. 94, 472-479.

Kudryavtsev, A. M., S. P. Martynov, M. Broggio, and V. A. Pukhalskiy, 2003: Relevance of RAPD analysis for revealing phylogenetic relationships between cultivar of durum wheat Triticum durum Desf. Russ. J. Genet. 39, 1043-1051. doi: 10.1023/ A: 1025779202500 .

Mackill, D. J., Z. Zhang, E. D. Redona, and P. M. Colowit, 1996: Level of polymorphism and genetic mapping of AFLP markers in rice. Genome 39, 969-977.

Manifesto, M. M., A. R. Schlatter, H. E. Hopp, E. Y. Suarez, and J. Dubcovsky, 2001: Quantitative evaluation of genetic diversity in wheat germplasm using molecular markers. Crop Sci. 41, 682-690.

Metakovsky, E. V., and G. Branlard, 1998: Genetic diversity of French common wheat germplasm based on gliadin alleles. Euphytica 96, $209-218$.

Nagaoka, T., and Y. Ogihara, 1997: Applicability of inter-simple sequence repeat polymorphisms in wheat for use as DNA markers in comparison to RFLP and RAPD markers. Theor. Appl. Genet. 94 $597-602$.

Nei, M., and W. Li, 1979: Mathematical model for studying genetic variation in terms of restriction endonucleases. Proc. Natl. Acad. Sci. U. S. A., 76, 5269-5273.

Ozkan, H., A. Brandolini, C. Pozzi, S. Effgen, J. Wunder, and F. Salamini, 2005: A reconsideration of the domestication geography of tetraploid wheat. Theor. Appl. Genet. 110, 1052-1060.

Pagnotta, M., L. Mondini, and M. Atallah, 2005: Morphological and molecular characterization of Italian emmer wheat accessions. Euphytica 146, 29-37.

Paul, J. G., K. J. Chalmers, A. Karakousis, J. M. Kretschmer, S. Manning, and P. Langridge, 1998: Genetic diversity in Australian wheat varieties and breeding materials based on RFLP data. Theor. Appl. Genet. 96, 435- 446

Plaschke, J., M. W. Ganal, and M. S. Röder, 1995: Detection of genetic diversity in closely related bread wheat using microsatellite markers. Theor. Appl. Genet. 91, 1001-1007.

Powell, W., M. Morgante, C. Andre, M. Hanafey, J. Vogel, S. Tingey, and A. Rafalski, 1996: The comparison of RFLP, RAPD, AFLP and SSR (microsatellite) markers for germplasm analysis. Mol. Breed. 2, 225-238.

Prevost, A., and M. J. Wilkinson, 1999: A new system of comparing PCR primers applied to ISSR fingerprinting of potato cultivars. Theor. Appl. Genet. 98, 107-112.

Rakoczy-Trojanowska, M., and H. Bolibok, 2004: Characteristics and a comparison of three classes of microsatellite-based markers and their application in plants. Cell. Mol. Biol. Lett. 9, 221-238.

Rholf, F. J., 1993: NTSYS-pc Numerical Taxonomy and Multivariate Analysis System. Exeter Software, Setauket, NY.

Roy, J. K., H. S. Balyan, M. Prasad, and P. K. Gupta, 2002: Use of SAMPL for a study of polymorphism, genetic diversity and possible gene tagging in bread wheat. Theor. Appl. Genet. 104, 465- 472.

Schut, J. W., X. Oi, and P. Stam, 1997: Association between relationship measures based on AFLP markers, pedigree data and morphological traits in barley. Theor. Appl. Genet. 95, 1161-1168. Shoaib, A., and M. I. E. Arabi, 2006: Genetic diversity among Syrian cultivated and landraces wheat revealed by AFLP markers. Genet. Resour. Crop Evol. 53, 901-906.

Sun, Q., T. C. Huang, Z. F. Ni, and J. D. Procunier, 1996: Study on wheat heterotic group. I. Genetic diversity revealed by random amplified polymorphic DNA (RAPD) in elite wheat cultivars. J. Agric. Biotechol. 4, 103-110.

Sun, Q., Z. Ni, Z. Liu, J. Cao, and T. Huang, 1998: Genetic relationships and diversity among Tibetan wheat, common wheat and European spelt wheat revealed by RAPD markers. Euphytica 99, 205-211.

Sun, G., M. Bond, H. Nass, R. Martin, and Z. Dong, 2003: RAPD polymorhisms in spring wheat cultivar and lines with different level of Fusarium resistance. Theor. Appl. Genet. 106, 1059-1067.

Swofford, D. L., 1998: PAUP: Phylogenetic Analysis Using Parsimony (and Other Methods). Sinauer Associates, Sunderland, MA.

Vos, P., R. Hogers, M. Bleeker, M. Reijans, T. van de Lee, M. Hornes, A. Frijters, J. Pot, J. Peleman, M. Kuiper, and M. Zabeau, 1995: AFLP: a new technique for DNA fingerprinting. Nucleic Acids Res. 23, $4407-4414$.

Witsenboer, H., J. Vogel, and R. W. Michelmore, 1997: Identification, genetic localization, and allelic diversity of selectively amplified microsatellite polymorphic loci in lettuce and wild relatives (Lactuca spp). Genome 40, 923-936.

Zencirci, N., and A. Karagöz, 2005: Effect of developmental stages length on yield and some quality traits of Turkish durum wheat (Triticum turgidum L. convar. durum (Desf.) Mackey) landraces: Influence of developmental stages length on yield and quality of durum wheat. Genet. Resour. Crop Evol. 52, 765-774. 